\title{
O FERRO NA HISTÓRIA: DAS ARTES MECÂNICAS ÀS BELAS-ARTES*
}

\author{
José Amado Mendes**
}

O ferro tem-se revestido de uma grande importância na História da Humanidade. A sua utilização, desde a Idade do Ferro propriamente dita, não mais deixou de se expandir, anto geograficamente como no que concerne às formas de aplicação. As suas características, quanto a resistência, maleabilidade e durabilidade, fazem dele o material adequado a uma série de aplicações. Assim, desde utensílios medievais, passando pelo armamento da Época Moderna, pela produção de maquinaria, com a industrialização e pelas numerosas edificações dos últimos dois séculos, a presença do ferro é uma constante. A arquitectura do ferro tornou- -se emblemática, na segunda metade do século XIX e nos inícios da nossa centúria. A possibilidade de moldagem fez do ferro fundido um material muito usado pela Arte Nova. Por sua vez, em ferro forjado executaram-se obras de arte de rara beleza, como grades, portões, candelabros e diversos tipos de mobiliário.

Palavras-chave: Ferro, ferro forjado, património, artes mecânicas, BelasArtes.

\footnotetext{
** Faculdade de Letras da Universidade de Coimbra; Pólo de Viseu do Centro Regional das Beiras da Universidade Católica Portuguesa; investigador do Centro de Estudos Interdisciplinares do Século XX (CEIS 20).
} 


\section{INTRODUÇÃO}

Com as profundas transformações operadas na historiografia no último meio século, os historiadores alargaram substancialmente o objecto da sua investigação. Assim, dém de batalhas, tratados, biografias de monarcas ou de príncipes ? que concentravam grande parte da atenção dos investigadores ?, estes passaram a debruçar-se também sobre assuntos relacionados com o dia-a-dia e com o comum dos mortais, desde o trabalho à vida privada, da alimentação ao vestuário, dos costumes aos diversos modos de lazer, para dar apenas alguns exemplos.

Assim, não surpreende que certos tópicos, outrora completamente ignorados ou, quando muito, focados apenas em notas de rodapé, passassem a dar origem a trabalhos de maior fôlego, através dos quais tem vindo a ser revelada parte substancial da história humana, até há pouco subalternizada. Entre muitos outros casos que poderiam referenciar-se, apenas recordo os seguintes:

? energia na história mundial ${ }^{1}$;

? história da electricidade e do abastecimento de água;

? alojamento operário;

? materiais de construção, como o tijolo e o betão;

? actividades relacionadas com a produção e circulação de bens, nomeadamente no âmbito do artesanato e da indústria, do comércio e das comunicações.

De acordo com estas tendências verificadas no campo da história ? mas que radicam, em última análise, em novas perspectivas filosóficas e ideológicas sobre o próprio homem ?, faz todo o sentido que nos debrucemos, aqui e agora, sobre esse material tão importante, como é o ferro e, bem assim, sobre os produtos, confeccionados a partir dele. 


\section{O FERRO NA HISTÓRIA DA HUMANIDADE}

O ferro é um corpo simples, sendo o mais abundante e o mais conhecido dos metais ${ }^{2}$. A sua importância, na história, desde há muito foi evidenciada pela arqueologia, inclusive ao classificar, como Idade do Ferro, uma determinada época da história da Humanidade. Como é sabido, o uso do ferro seguiu-se ao do cobre e do bronze, embora estes metais tivessem continuado a ser usados, juntamente com aquele. Em termos cronológicos, o homem conhece as formas de tratamento do minério de ferro desde cerca de 1200 a. C. Foi no Médio Oriente que a respectiva tecnologia começou a ser usada. No Norte da Europa, a Idade do Ferro começou por volta de 700a.C. e, na Península Ibérica, cerca de 1000-900 a. C., graças aos Celtas, tendo-se verificado a sua difusão a partir do século VII ${ }^{3}$.

Ao longo da Idade Média, o ferro começou a desempenhar um papel algo relevante, com a expansão da charrua, com relha de ferro, e da ferradura, para o cavalo, então de importância decisiva nos transportes, na paz como na guerra ${ }^{4}$. Em finais da época medieval ? meados do século XV ? , o quotidiano do homem era profundamente marcado pela seguinte trilogia:

? a madeira (daí a importância da floresta);

? a água (no consumo, humano e animal, na agricultura e nas actividades manufactureiras, em operações várias e, também, como força motriz);

? o ferro ${ }^{5}$.

Todavia, ainda durante a Idade Média, o ferro continuou a usar-se com parcimónia, fundamentalmente em armas, ferramentas e armadura ${ }^{6}$, ou em acessórios, como cravos, dobradiças, fechaduras e grampos para união de alvenarias de pedra. Com efeito, até finais de Setecentos ? advento da primeira revolução industrial ?, o ferro continuou a ser um bem raro, devido a limitações de ordem tecnológica, como veremos entretanto.

Estava-lhe, porém, reservada uma função decisiva, nas duas centúrias posteriores. A propósito, já se afirmou ter sido o ferro «a base de todo o desenvolvimento industrial moderno» ${ }^{7}$, como também já se classificou o século XIX como o «da civilização do ferro» ${ }^{8}$. O mesmo se poderá dizer, em certa medida, do século XX ? se utilizarmos o termo "ferro" em sentido lato, incluindo o próprio aço ? , não obstante os novos materiais entretanto descobertos e largamente utilizados. Recordo, por exemplo, todo o tipo de máquinas ou alguns dos respectivos componentes, veículos de todo o género, estruturas várias ? inclusive as de betão, que se tornaram as mais comuns ao longo da nossa centúria, mas que não podem prescindir do ferro 
?, utensílios diversos, usados em circunstâncias variadas, desde as alfaias agrícolas ou industriais, ou mesmo nos lares. Nestes, pense-se não só nos electrodomésticos como na própria cutelaria, ainda não substituída pela de plástico, embora já se nos deparem experiências, em tal sentido.

Como lembra um autor inglês, na interessante obra intitulada The Power of the Machine ${ }^{9}$, «a civilização ocidental permaneceu ? e continua ? baseada nas técnicas do trabalho do ferro» ${ }^{10}$.

Em suma, pode corroborar-se aquilo que foi sublinhado, em 1995, num encontro internacional sobre a temática, realizado na Suécia: « há um desajustamento entre a grande importância do ferro e o pouco avanço no conhecimento arqueológico, histórico e técnico sobre o mesmo $»^{11}$.

Para não irmos mais longe, basta lembrar as colunas que suportam a chaminé da cozinha do Mosteiro de Alcobaça, as quais ainda constituem um certo enigma, não só para investigadores portugueses como também para alguns estrangeiros, nomeadamente ingleses.

\section{CONDICIONALISMOS TECNOLÓGICOS NA UTILIZAÇÃO DO FERRO}

Nas civilizações clássicas e medievais, como afirma Geraldo Gomes da Silva ? na sua interessante obra, Arquitectura do ferro no Brasil ? , o ferro era muito caro, devido ao processo artesanal utilizado. $O$ ferro era então feito em fornalhas, pelo que a quantidade produzida era pequena ${ }^{12}$. Recorria-se, então, ao "processo directo", que consistia em obter o ferro directamente do minério ? sem passar pela gusa ? , através do carvão de madeira. Obtinha- -se uma massa, que era martelada, para aumentar a sua compactidade. ${ }^{13} \mathrm{Na}$ Baixa Idade Média e na transição desta para a Idade Moderna, foram introduzidas importantes inovações nas artes do ferro. Refiro-me, nomeadamente, à chamada "forja catalã", ao "alto-forno" e ao "processo indirecto".

O forno ou forja catalã ? que começa a funcionar entre os séculos IX e XI ? consistia na utilização de um cadinho, bem como no recurso ao carvão de madeira e ao ar, para a obtenção do ferro, a partir do respectivo minério ${ }^{14}$. Mesmo assim, através de uma operação de 4 ou 5 horas, não se obtinham mais de 30 a $40 \mathrm{~kg}$. de ferro ${ }^{15}$. Entretanto, provavelmente já a partir dos séculos XI-XII, a energia hidráulica começou a ser aplicada às forjas, para accionar os respectivos foles ${ }^{16}$. Estes foles mecânicos, accionados pela água, permitiam manter a temperatura elevada acima do ponto de fusão do ferro, possibilitando a produção de ferro moldado, com 
uma grande variedade de formas, incluindo canhões para a artilharia e colunas para construções ${ }^{17}$. Foi também aquela inovação que contribuiu para o desenvolvimento do alto- -forno ? a partir dos séculos XIV-XV ? que chegava a atingir, por vezes, 20 metros de altura ${ }^{18}$.

Pela mesma época e intimamente relacionado com o alto-forno, surgiu o processo indirecto na produção de ferro, que consiste no seguinte:

a) produção de lingotes (ferro fundido), a alta temperatura $\left(1400^{\circ} \mathrm{c}\right.$.), num alto-forno;

b) neste, o ferro é completamente liquefeito;

c) depois solidifica, vai à forja, na qual, com carvão e ar, é refinado ${ }^{19}$.

Já nos inícios do século XVIII ? mais precisamente em 1709 ? , no forno de Abraham Darby I, em Coalbrookdale (Grã-Bretanha), dá-se mais um passo importante, para o avanço da tecnologia do ferro. É que, pela primeira vez, se produzia ferro, utilizando carvão de pedra ${ }^{20}$. O processo ficava, assim, liberto das florestas. Pode dizer-se que começava então, no que ao ferro diz respeito, a revolução industrial. Contudo, para que esta se completasse, faltava ainda a máquina a vapor, cuja patente viria a ser registada, por James Watt, em 1769.

\section{DA REVOLUÇÃO INDUSTRIAL À "CIVILIZAÇÃO DO FERRO”, NO SÉCULO XIX}

O uso da hulha ? para a redução do minério de ferro ? e da energia a vapor transformou completamente as condições de produção do ferro. De facto, aquela permitiu que países, ricos em minas de carvão ? como a Inglaterra e, mais tarde, a Alemanha ? , passassem a dispor de vantagens acrescidas no ramo da siderurgia. Quanto à máquina a vapor, a sua utilização revelou-se da maior utilidade nas várias fases da extracção do minério de ferro (acesso dos mineiros às minas, extracção de água e transporte do minério), assim como na produção e no transporte do próprio ferro. Mas o uso da referida máquina ? à qual o historiador francês, Pierre Ducassé, chamou, com inteira propriedade, "escravo mecânico" ? tornou-se ainda decisivo em numerosas indústrias, incluindo a metalomecânica, grande consumidora de ferro, na produção de maquinaria e de utensílios diversos.

Assim, pode dizer-se que em praticamente todos os domínios que, no século passado, sofreram transformações consideráveis, o ferro esteve presente. Entre outros, considerem-se os seguintes exemplos: 
? caminho-de-ferro (vias e material circulante, desde as poderosas locomotivas às requintadas carruagens, estações e estruturas anexas, pontes, etc.). Foi aquele que, durante décadas, mais contribuiu para o desenvolvimento da siderurgia;

? edifícios (industriais, mercados, armazéns, estruturas portuárias e outros equipamentos colectivos);

? abastecimento (de água, gás e, posteriormente, electricidade) e saneamento básico;

? construção naval (desde as pequenas embarcações aos gigantescos "vapores", cujo casco e outras estruturas passaram a ser de ferro e/ou de aço).

Para o rápido sucesso verificado na divulgação do ferro, as suas características e potencialidades tornaram-se decisivas. Tratava-se de um material que, pelo seu maior coeficiente de resistência, em relação aos materiais tradicionais ? pedra e madeira ?, permitia não só diminuir o número de suportes, como o de colunas ou pilares (cuja secção era também mais reduzida), com a consequente obtenção de grandes vãos. Estes facilitavam a instalação de maquinaria de enormes proporções, nas fábricas, ao mesmo tempo que permitiam reduzir o custo da construção, tanto naquelas como nas pontes, além de deixarem os leitos dos rios mais libertos para a navegação. Recorde--se o grande vão da nossa Ponte de Maria Pia, no Porto ? construída de 1875 a 1877, pela empresa de Eiffel ? , jóia da arquitectura do ferro e importante monumento industrial, à espera de uma reutilização condigna.

O ferro permitia reduzir também o risco de incêndio, flagelo frequente das fábricas na primeira fase da industrialização, ao mesmo tempo que resistia melhor aos sismos. Aquele possibilitava, ainda, a rápida montagem e desmontagem, isto é, o uso do pré-fabricado, o que se tornou decisivo para diminuir o tempo de edificação de grandes estruturas. Como exemplos, basta lembrar o famoso Crystal Palace, em Londres (1851), ou a não menos emblemática Torre Eiffel, em Paris (1889).

Do ponto de vista técnico, o ferro oferecia igualmente condições favoráveis à aplicação de novos conhecimentos, no que concerne à resistência de materiais. A propósito, já foi salientado: «Com a contribuição progressiva da ciência moderna da resistência de materiais, o uso de metal torna-se sinónimo de calculabilidade, uma calculabilidade que as obras tradicionais, em alvenaria, estavam longe de poder suportar» ${ }^{21}$.

$\mathrm{O}$ que se acaba de expor, acerca da excelência do ferro como material de construção, foi devidamente evidenciado, de forma prática, na realização de grande número de obras. Estas serviam não só como demonstração do que, 
com o ferro, era possível fazer, mas também como "cartazes publicitários", de grande eficácia, ou mesmo como "ex libris" de certos locais ou eventos. Recordem-se, por exemplo: a) a primeira ponte de ferro construída no mundo (1776-79), em Coalbrookdale/Ironbridge (Grã-Bretanha); b) o já referido "Crystal Palace", em Londres, para albergar a emblemática Exposição universal de 1851, a primeira das grandes "festas da

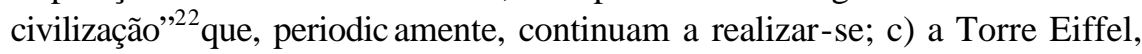
em Paris, inaugurada aquando da Exposição Universal de 1889 ? comemorativa do $1^{\circ}$ centenário da Revolução Francesa de 1789 ? , a qual, após as reticências de alguns dos seus contemporâneos, viria a tornar-se como que na "imagem de marca " da capital francesa.

Acrescente-se, no entanto, que o uso do ferro viria a prosseguir no século XX, como, certamente, prosseguirá na centúria que se aproxima. É que, mesmo após a quase omnipresença do betão ? a partir dos inícios do presente século ?, e não obstante o ferro the continuar associado, como vimos já, as construções em metal continuam a ter o seu lugar, tanto na arquitectura industrial ${ }^{23}$, como em diversos outros domínios ${ }^{24}$.Como um dos casos emblemáticos, da arquitectura metálica das últimas décadas, pode referir-se o Centro Pompidou, em Paris, edificado de 1972 a 1977. Embora também com a aplicação de outros materiais, como o titânio, caso não menos significativo é ainda o novel e fantástico Museu Guggenheim, em Bilbau.

\section{O FERRO NA ARTE}

Os trabalhos em ferro ? a exemplo do que sucede com a cerâmica e o vidro ? integram-se nas chamadas artes do fogo. Muitos dos objectos em ferro, produzidos artesanalmente, apresentam certas componentes artísticas, pois, além de peças únicas ? feitas uma a uma e, do princípio ao fim, pelo mesmo artífice ?, muito se identificam com o gosto do artesão, designadamente o ferreiro ou o serralheiro.

O ferro forjado, já usado nos tempos medievais, obtido directamente do minério, era mais maleável ${ }^{25}$. Por seu turno, o ferro fundido, usado já pelo final da Idade Média, em armamento, veio depois a alcançar grande êxito, com a revolução industrial, vindo a superar o ferro forjado. $\mathrm{O}$ sucesso deste deveu-se a vários factores, de entre os quais se destacam:

a) é mais barato;

b) é também mais resistente, mais forte (embora seja igualmente mais quebradiço); 
c) permite a moldagem, apresentando imensa flexibilidade decorativa, o que se tornou essencial, por exemplo, na "Arte Nova" ${ }^{26}$;

d) possibilita, também, a estandardização do processo produtivo, o que se tornou fundamental na siderurgia praticada com a revolução industrial, com a necessidade de produzir em larga escala. A inovação do processo Bessemer, na produção de aço (anos 1850), também permitiu desenvolver substancialmente as construções metálicas.

Como se deduz do exposto, tanto o ferro forjado como o ferro fundido têm sido usados na produção artística. Contudo, enquanto este se adequa melhor à produção em massa, ou seja, em série e repetitiva ? possibilitada pela moldagem ? , já o ferro forjado se adapta preferentemente ao trabalho artístico individual, no qual há uma certa identificação entre produtor e produto. Tratava-se de um saber-fazer transmitido, regra geral, de mestre a aprendiz, embora, uma ou outra vez, também tivesse sido objecto de ensino nas escolas ${ }^{27}$.

Sobre os dois produtos de ferro mencionados parece-me feliz a caracterização efectuada por Luís Chaves: "“As grades" de ferro forjado estão para as fundidas como a renda está para o bordado» ${ }^{28}$.

\section{AS ARTES DO FERRO EM COIMBRA: PATRIMÓNIO A ESTUDAR E REVALORIZAR}

Dada a vastidão da temática e uma vez que me propus focar aspectos de carácter mais geral e de enquadramento, aqui apenas farei algumas considerações acerca dos seguintes tópicos: estabelecimentos produtivos e produtores; produtos de tipo variado; e património e saber-fazer.

\subsection{Oficinas e produtores}

Coimbra, a "cidade das grades", como the chamou Vergílio Correia ${ }^{29}$, tinha produção de ferro própria, embora insuficiente, para certas necessidades. Por exemplo, parte da estrutura de ferro da estufa do Jardim Botânico veio da Fundição de Massarelos, do Porto ${ }^{30}$.

Com o intensificar do uso do ferro fundido, a partir de meados de Oitocentos, não surpreende que as oficinas localizadas em Coimbra se tivessem dedicado mais à obra em ferro fundido do que em ferro forjado. Contudo, ainda na segunda metade daquela centúria, se encontram algumas 
referências ao ferro forjado. Assim, José Bernardes Galinha apresentou, na Exposição Distrital de Indústria Agrícola e Fabril e de Arqueologia (Coimbra, 1869), vários objectos de ferro fundido (fogões, inclusive um para trabalhar com gás, panelas, compassos, «c.), mas também «dois varões de ferro sextavados, e só forjados, para amostra $»^{31}$.

Aquele, falecido em 1873, fez parte de uma dinastia célebre de artistas do ferro que, ao longo de quatro ou cinco gerações (desde Manuel Bernardes Galinha, autor do conhecido portão do Jardim Botânico, que falecera em 1864, e o seu descendente, Joaquim Ferreira Galinha, que viria a morrer em 1924), se dedicaram, em Coimbra, às artes do ferro ${ }^{32}$.

Já no que concerne a outras oficinas, além de se mencionarem diversos tipos de objectos ou utensílios produzidos, em vários casos se refere, expressamente, a existência de fundição. Vejamos alguns exemplos:

? Oficina de carruagens, na rua da Sofia, de Manuel da Costa Soares $(1876)^{33}$.

? José Alves Coimbra e seu irmão, António Alves Coimbra, com estabelecimento no Largo das Ameias, de fronte do Hotel Mondego (1879), onde faziam qualquer obra de ferro fundido (panelas, testos, fogareiros, fornalhas), encontrando-se, alguns anos mais tarde (1888), a produzir para o mercado de Lisboa ${ }^{34}$.

? Oficina de serralharia, de António Bernardes Galinha (Rua de Quebra Costas, 29), na qual, além do mais, se produziam «camas de ferro, de novo gosto, superiores às de Lisboa e do Porto» ${ }^{35}$.

? Joaquim Augusto das Neves Eliseu (morador na Rua das Figueirinhas, 21), com a produção de vários objectos, em folha maneável ou por fundição ${ }^{36}$.

? Oficina de Serralharia a Vapor, de Eduardo \& Almeida (Rua da Madalena) que, além de outros artigos, produzia máquinas a vapor (de $1 \mathrm{a} 15 \mathrm{cv}.)^{37}$.

Pelos exemplos que acabo de referir, pode deduzir-se que, a avaliar pela oferta de diversos artigos, a "civilização do ferro" também ia chegando a Coimbra. Isto não obstante a lentidão com que, nas construções, a madeira ia cedendo o lugar ao metal. Assim, numa fonte dos finais do século (1894), pode ler-se:

«Compreende-se que as construções civis ainda não dêem entre nós um grande consumo ao aço, sob a forma de vigas, por exemplo, em que preenche o uso da madeira; começa-se a notar, no entanto, que algumas das mais cuidadas edificações, a despeito do sistema tradicional e tido entre nós como o melhor para prevenir os efeitos de certos acidentes, têm já empregado o vigamento metálico» ${ }^{38}$. 
Em 1920, duma escritura de partilhas de bens, situados na Baixa de Coimbra, constam cinco serralharias localizadas, respectivamente, nas ruas do Arnado (3), da Nogueira (1) e da Madalena (1). Na Rua do Arnado situava-se ainda uma fundição ${ }^{39}$.

Naturalmente que muito mais há a investigar, quanto a oficinas/manufacturas metalomecânicas, em Coimbra, a saber:

a) levantamento de todas as que laboraram, não só em determinada altura como a longo prazo;

b) recursos, humanos e materiais, com que puderam contar;

c) tecnologia, própria ou importada que utilizaram;

d) métodos de gestão, formação de pessoal, mercado, etc.

Acerca de produtores/profissionais das artes do ferro, a exploração de certas fontes ? entre as quais registos paroquiais e notariais ? fornecem-nos algumas informações, pelo que o seu estudo deve prosseguir. Contudo, também noutras se podem detectar dados com interesse. Por exemplo, a consulta dos registos de enterramentos no Cemitério da Conchada (18601930) permite tirar, entre outras, as seguintes ilações:

a) Dos indivíduos (sepultados no dito cemitério) que haviam exercido profissões ligadas ao ferro (ferreiro, serralheiro e fundidor), no período em foco, o número dos primeiros era geralmente baixo e foi diminuindo; o dos fundidores também era reduzido, ao passo que o dos serralheiros foi aumentando, especialmente já no século XX. Assim, enquanto no século passado era registado o enterramento de 2 ou 3 serralheiros, num período de 2 ou 3 anos, em 1918-19 já aparecem 3 serralheiros e 2 serralheiros mecânicos e, em 1920-21, o número de serralheiros sepultados sobe a 7 .

b) Para o final do lapso de tempo em foco (primeiras décadas do século $\mathrm{XX}$ ), começam igualmente a aparecer novas profissões: mecânico (em 1915, um cidadão de naturalidade francesa e, em 1918, já dois portugueses); e metalúrgico (em 1927, natural da Feira, freguesia de Anta).

No que ao ferro forjado diz respeito, foi também a partir dos inícios do século que aquela arte mais se desenvolveu, graças à Escola Livre das Artes do Desenho (criada em 1878) e ao Mestre António Augusto Gonçalves. Este, ao visitar a Exposição Universal de Paris de 1900, teve o ensejo de apreciar «algumas maravilhas trabalhadas no duro metal, especialmente por artistas espanhóis $»^{40}$. 


\subsection{Produtos metálicos}

Infelizmente ainda não dispomos de obra de conjunto sobre a arquitectura do ferro, em Portugal, ao invés do que já sucede em alguns outros países. Enquanto esperamos por esse trabalho ? ou mesmo por outros mais restritos, sobre a arquitectura industrial do ferro, pontes ou outras estruturas metálicas ?, seria vantajoso que se prosseguisse com a elaboração de estudos de caso, a nível regional e local, que ficariam a constituir achegas com interesse para futuras obras de síntese.

Será, contudo, da maior importância que a investigação se alargue a diversos tios de produtos e que não se restrinja aos mais conhecidos e aos que, pela sua volumetria e/ou localização, dão mais nas vistas. Além de estruturas de maior porte ? edifícios, mercados, estações ferroviárias, fábricas e $\operatorname{coretos}^{41}$, etc. ? , deve atentar-se ainda noutro tipo de objectos, designadamente: colunas de suporte (por exemplo, em $\mathbf{L}$ ou em T), fogões de sala, grades, portões ou varandas, candeeiros e outro mobiliário urbano ou ainda elementos funerários, em portões, jazigos ou mausoléus.

Há já algum tempo (1987), num interessante estudo sobre $O$ ferro forjado na história e na arte da cidade do Porto, a autora, Susana Flor, chamava a atenção para números, em ferro forjado, colocados nas edificações, com a respectiva data. A propósito escrevia: «Estes preciosos ornamentos incrustam-se em pequenas elipses, rectângulos ou círculos, no centro das varandas, no centro da parte superior dos portões, e ainda nas cancelas e bandeiras de porta das edificações urbanas portuguesas, pertencendo na quase totalidade à segunda metade do século XIX ». A autora descobriu, no Porto, 22 destes motivos tipológicos (datados de 1852 a 1949$)^{42}$.

\subsection{O ferro como património e saber-fazer a preservar e revalorizar}

Já em 1906, Joaquim Martins Teixeira de Carvalho (Quim Martins), no trabalho intitulado «Os serralheiros da Escola de Coimbra» ${ }^{43}$, aludia a nomes destacados da arte do ferro forjado, alguns deles discípulos de António Augusto Gonçalves. Começa por se referir a Manuel Pedro de Jesus e a João Machado, que considerava cooperadores daquele mestre, «nesta obra de ressurgimento artístico» ${ }^{44}$. Menciona outros nomes, como António Maria da Conceição, António Couceiro e Lourenço d'Oliveira Chaves de Almeida, arquitecto Augusto da Silva Pinto Joaquim Mendes de Abreu e Joaquim Abreu Couceiro. Ao concluir o seu artigo, Quim Martins sublinhava: 
«E é, em minha opinião, o ensino de António Augusto Gonçalves o único que, no nosso país, mostra a compreensão inteligente das preocupações pedagógicas que têm reformado completamente no estrangeiro a educação artística do operário» ${ }^{45}$.

Como é sabido, a estes grandes mestres do ferro forjado, em Coimbra, outros se sucederam, ao longo de cerca de três quartos de século. A sua vida e obra constituem património cultural de grande relevância, sem esquecer um saber-fazer, ancestral, que é hoje pouco conhecido e divulgado.

Além do estudo da obra feita por aqueles, devia manter-se viva a tradição, em oficina a funcionar nos moldes tradicionais, que fosse não só um museu vivo, mas também um centro pedagógico e cultural.

Antes de concluir apenas gostaria de prestar a minha singela homenagem a um grande mestre do ferro forjado, que foi José Pompeu Aroso (13.7.1910--26.2.1986). Trabalhou o ferro desde os 14 anos de idade e dedicou-se à arte do ferro forjado até ao fim dos seus dias. Em 1984 foralhe atribuída a Medalha de Ouro da cidade de Coimbra.

Foi para mim uma experiência inesquecível ter visitado a sua oficina, tendo-o como guia, em Fevereiro de 1982. Ao tempo, o Mestre Pompeu Aroso ainda alimentava uma esperança, embora ténue, de os seus colaboradores poderem vir a manter a oficina em laboração, mesmo após o seu desaparecimento. Isso, infelizmente, não se verificou.

Entretanto ofereceu-me, gentilmente, uma síntese da sua biografia, em verso, datada de 47-1978, à qual deu o título «É assim uma vida». É com esse testemunho, que considero de relevância para o conhecimento do homem e do artista, no seu percurso por este mundo, que termino este trabalho. 


\section{É ASSIM UMA VIDA}

Nasci de uma coligação

Das cidade principais

Donde surgiu altercação

De litígio de meus Pais

Filho por tradição

Do trabalho e das culturas

Tenho com recordação

Meus pais nas sepulturas

Meu Pai veio do Porto

Saudosa Mãe de Lisboa

Sou de Coimbra de ferro torto

Tenho os brasões em pessoa

Mestres Machados e Gonçalves Pioneiros de Belas Artes

Chaves de Almeida e Rodrigues

E saudoso Albertino Marques

Com amor e sacrifício

De muitos anos vincados

Este serralheiro de ofício

Aquém dos seus antepassados

Autor de vários cinzeiros

O carro de mão e o gato

É do signo dos caranguejos

E do bacalhau sem pataco

Ferro frio mal tratado

Quando se pensa em casa

Para ser bem forjado

Só obedece estando em brasa
Nada tenho nada valho

Por tudo aquilo que fiz.

De bigorna martelo e malho

Neste século dos xis-xis

O' Coimbra minha terra

Da cultura e da arte

Da tradição o que se espera

É deixar morre a "Forjarte" Eu trabalho sim senhor

Quando não tenho que fazer

Luto sempre com amor

Sempre e sempre até morrer

Nunca fui compreendido

Talvez maneiras de ver

Nem os que convivem comigo

Me sabem compreender

Sou do signo caranguejo

Dois à frente e dois atrás

Só preciso viver em paz.

A vida é uma saudade

Em que tudo é mentira

Aguardando com verdade

O que ela nos inspira

Esta Coimbra madrasta

A quem tudo os filhos dão

Com os outros tudo gasta

E os seus morrem sem pão

Desde os oito a trabalhar

Mais sessenta de passado

Posso comer e guardar

Com o que fui reformado

$$
\text { 4-7-78 }
$$

[José Pompeu Aroso] ${ }^{46}$ 


\section{NOTAS}

* O texto que ora se publica, ampliado e anotado, foi inicialmente apresentado às I Jornadas subordinadas ao tema Escola do Ferro de Coimbra, realizadas nesta cidade nos dias 11 e 12 de Dezembro de 1999.

${ }^{1}$ A propósito, ver o interessante estudo de Vaclav Smil, Energy in Word History, Boulder, San Francisco, Oxford, Westview Press, 1994.

2 «Ferro», Grande Enciclopédia Portuguesa e Brasileira, vol. XI, Lisboa-Rio de Janeiro, p. 211.

3 Jorge Custódio e G. Monteiro de Barros, O ferro de Moncorvo e o seu aproveitamento através dos tempos, Moncorvo, Ferrominas, EP, 1984, p. 16; «Ferro», art. cit., p. 212.

${ }^{4}$ J. Custódio e G. M. de Barros, op. cit., p. 17.

${ }^{5}$ Philippe Brausntein, «The forest, the iron and the water. Perspectives on development of European economies in the end of the Middle Ages», Gert Magnusson (ed.), The Importance of Ironmaking. Technical Innovation and Social Chug, vol. II: Papers presented at the Norberg Conference on May 8-13, 1995, Estocolmo, Jerkontorets/Bergshistoriska Utskott, 1996, p. 159.

${ }^{6}$ Geraldo Gomes da Silva, Arquitectura do ferro no Brasil, São Paulo, Livraria Nobel, p. 11 .

${ }^{7}$ «Ferro», art. cit., p. 214.

${ }^{8}$ G. G. da Silva, op. cit., p. 11.

${ }^{9}$ R. A. Buchanan, The Power of the Machine. The impact of technology from 1700 to the present day, Londres, Penguin Books, 1992, p. 16

${ }^{10}$ Idem, p. 16.

${ }^{11}$ Neil Cossons, «Ironmaking sites: Conservation and interpretation», op. cit. supra, nota 5, p. 213.

${ }^{12}$ Op. cit., p. 13.

13 «Ferro», art. cit, p. 215.

${ }^{14}$ Idem, p. 215; J. Custódio e G. M. de Barros, op. cit., p. 18.

15 «Ferro», art. cit., p. 215.

${ }^{16}$ J. R. Harris, The British Iron Industry 1700-1850, Londres, Macmillan Education, 1988, p. 12.

${ }^{17}$ R. A. Buchanan, op. cit., p. 15-16.

${ }^{18}$ J. Custódio e G. M. de Barros, op. cit., p. 18.

${ }^{19}$ J. R. Harris, op. cit., p. 13.

${ }^{20}$ Ibidem.

${ }^{21}$ Frédéric Seitz, Architecture et métal en France. 19e-20e siécles, Paris, Éd. De l'École des Hautes Études en Sciences Sociales, 1994. 
22 José Amado Mendes, «As exposições como "festas da civilização": Portugal nas Exposições Internacionais (sécs. XIX-XX)», Gestão e desenvolvimento, 7, 1998, p. 249- 273.

${ }^{23}$ Julian Sobrino, Arquitectura industrial en España, 1830-1990, Madrid, Ed. Cátedra, 1996.

${ }^{24}$ Frédéric Seitz, L'architecture métalique au XX siécle. Architecture et "savoire- faire”, Paris, Ed. Belin, 1995.

${ }^{25}$ John Gay, Cast iron. Architecture and ornament, function and fantasy, Londres, John Murray (Publishers), 1985, p. 8.

${ }^{26}$ J. Gay, idem, p. 8-9.

${ }^{27}$ É provável que fizesse parte do ensino dedicado ao ferro no "Conservatoire d'Arts et Métiers" de Paris, embora as componentes essencialmente contempladas fossem: a engenharia/resistência de materiais, a estética (os aspectos formais) e a combinação entre as duas (F. Seitz, Architecture et métal en france, p. 78-79). Também na Escola Livre da Artes do Desenho se lhe dedicou (em especial ao ferro forjado) certa atenção, sob o impulso de António Augusto Gonçalves.

${ }^{28}$ Citado por Augusto Abreu Lopes Cepeda, Ferros artísticos de Penafiel, Penafiel, 1994, p. 8.

${ }^{29}$ Vergílio Correia, «A cidade das grades», Obras, vol. I: Coimbra, Universidade de Coimbra, 1946, p. 363-367.

${ }^{30}$ Ana Maria Cardoso de Matos, «A indústria metalúrgica e metalomecânica em Lisboa e no Porto, na segunda metade do século XIX», Arqueologia e Indústria, 1, Julho 1998, p. 97.

${ }^{31}$ Exposição Districtal de Industria Agricola e Fabril e de Archeologia, promovida pela Associação dos Artistas de Coimbra, sob a presidencia de Olympio Nicolau Ruy Fernandes, Coimbra, Imprensa da Universidade, 1869, p. 159 (itálico meu).

${ }^{32}$ Arquivo da Universidade de Coimbra (AUC), «Cemitério da Conchada. Registo de enterramentos».

${ }^{33}$ Conimbricense, de 18.4.1876.

${ }^{34}$ Idem, de 17.6 .1879 e de 15.9.1888.

${ }^{35}$ Idem, de 4.3.1882 e de 24.3.1882.

${ }^{36}$ Idem, de 6.7.1883.

${ }^{37}$ Idem, de 30.5.1893.

38 «Introdução de novas industrias», Revista de obras Publicas e Minas, t. XXVII, números 291e 292, Março e Abril de 1894, p. 140-141.

${ }^{39}$ AUC, notário Eduardo Saldenha da Silva Vieira, liv. de notas n. ${ }^{\circ} 190-A$, fls. 58- 66v. (escritura de 15.6.1920).

${ }^{40}$ Rocha Pato, «Impõe-se revitalizar em Coimbra a arte tradicional do ferro forjado», Diário Popular, de 16.11.1978. 
${ }^{41}$ Sobre o de Coimbra, ver Regina Anacleto, O Coreto do Parque Dr. Manuel Braga em Coimbra, Coimbra, 1983. Sep. de «Mundo da Arte », n. ${ }^{\circ} 14$.

${ }^{42}$ Susana Flor, «O ferro forjado na história e na arte da cidade do porto», ARPPA, N. ${ }^{\circ} 2,2^{\circ}$ Semestre de1987, p. 22-24.

43 Joaquim Martins Teixeira de Carvalho, «Os serralheiros da Escola de Coimbra», Illustração Portugueza, 2a série, vol. II, 1906, p. 314-318.

${ }^{44}$ Idem, p. 314. Artistas do ferro forjado de Coimbra, além de abastecerem a cidade, produziam para diversos outros pontos do país: Lisboa, Batalha, Aveiro, etc. A propósito de alguns trabalhos executados para esta última cidade, ver Manuel Ferreira Rodrigues e Óscar Graça, «Pistas para a compreensão das manifestações "Arte Nova” em Aveiro: Cenografia, modernidade e tradição», comunicação apresentada ao Seminário LusoFrancês sobre História da Arquitectura e do Urbanismo. As Arquitecturas do Crescimento, mimeog.

${ }^{45}$ Idem, p. 318.

${ }^{46}$ Efectuei algumas correcções ortográficas. Os versos autobiográficos, que se acabam de transcrever, foram anteriormente publicados por Noémia Barreto Metello Leitão e José Machado Lopes, no artigo «Ferros de Coimbra. Mestre Pompeu Aroso, a magia da forja», Pampilhosa. Uma terra e um Povo, n. ${ }^{\circ}$ 15, Junho 1996, p. 48 (Agradeço, ao Dr. José Machado Lopes, esta informação).

\section{BIBLIOGRAFIA}

ANACletO, Regina (1983), O Coreto do Parque Dr. Manuel Braga em Coimbra, Coimbra. Sep. de «Mundo da Arte», n. ${ }^{\circ} 14$.

BUCHANAN, R. A (1992), The Power of the Machine. The Impact of the Technology from 1700 to the Present Day, Londres, Penguin Books.

CARVALHO, Joaquim Martins Teixeira de (1906), «Os serralheiros da Escola de Coimbra», Illustração Portugueza, 2. ${ }^{a}$ série, vol. II, p. 314-318.

BRAUNSTEIN, Philippe (1996), «The Forest, the Iron and the Water. Perspectives on the Development of European Economies in the End of the Middle Ages», Gert Magnusson (ed.), The Importance of Ironmaking. Technical Innovation and Social Change. Papers presented at the Norberg Conference on May 8-13, 1995, vol. II, Estocolmo, Jernkontorets/Bergshistoriska Utskott.

CEPEDA, Augusto Abreu Lopes (1994), Ferros artísticos de Penafiel, Penafiel, ACEL ? Equipamentos Abreu Cepeda Lda. 
CORREIA, Vergílio (1946), «A cidade das gradas», Obras, vol. I: Coimbra, Coimbra, por ordem da Universidade, p. 362-367.

CUSTÓDIO, Jorge e BARROS, G. Monteiro de (1984), O ferro de Moncorvo e o seu aproveitamento através dos tempos, Moncorvo, Ferrominas EP.

Exposição Districtal de Industria Agricola e Fabril e de Archeologia promovida pela Associação dos Artistas de Coimbra, sob a presidencia de Olympio Nicolau Ruy Fernandes (1869), Coimbra, Imprensa da Universidade.

«Ferro» (s/d), Grande Enciclopédia Portuguesa e Brasileira, vol. XI, Lisboa-Rio de Janeiro, Editorial Enciclopédia, p. 211-221.

FLOR, Susana (1987), «O ferro forjado na história e na arte da cidades do Porto», Arppa, n. ${ }^{\circ} 2$, p. $22-24$.

GAY, John (1985), Cast Iron. Architecture and Ornament, Function and Fantasy, Londres, John Murray (Publishers).

GOMES, Francisco Magalhães (1983), História da siderurgia no Brasil, São Paulo, Editora Italiana Limitada/Editora da Universidade de São Paulo.

HARRIS, J. R. (1988), The British Iron Industry 1700-1850, Londres, Macmillan Education, Ltd.

LEITÃO, Noémia Barreto Metello e LOPES, José Machado (1996), Pampilhosa. Uma Terra e um Povo, n. 15, p. 41-48.

LABORDE, Marie Françoise (1998), Architecture industrielle. Paris \& environs, Paris, ed. Parigramme.

MATOS, Ana Maria Cardoso (1998), «A ndústria metalúrgica e metalomecânica em Lisboa e no Porto na segunda metade do século XIX», Arqueologia \& Indústria, n. ${ }^{\mathrm{o}} 1$, p. $83-100$.

MENDES, José Amado (1998), «As Exposições como "Festas da Civilização": Portugal nas Exposições Internacionais (Sécs. XIX-XX)», Gestão e Desenvolvimento, 7 , p. 249-273.

PATO, Rocha (1978), «Impõe-se revitalizar em Coimbra a arte tradicional do ferro forjado», Diário Popular, supl. "Letras e Artes”, de 16.11.1978, p. VII e XIV.

Patrimoine de l'industrie. Ressources, pratiques, cultures, 1, 1999.

RODRIGUES, Manuel Ferreira e GRAÇA, Óscar, «Pistas para a compreensão das manifestações "Arte Nova” em Aveiro: Cenografia, modernidade e tradição». Comunicação ao Seminário Luso-Francês sobre História da Arquitectura e do Urbanismo, subordinado ao tema As Arquitecturas do Crescimento, realizado na Universidade de Aveiro, em 1 de Outubro de 1997 (mimeog.).

SANTOS, José Coelho dos (1989), O Palácio de Cristal e a Arquitectura do Ferro no Porto em meados do séc. XIX, Porto, Fundação Eng. António de Almeida.

SEITZ, Frédéric (1994), Architecture et métal en France. $19^{e}-20^{e}$ siécles, Paris, Éditions de l'École des Hautes Études en Sciences Sociales. 
SEITZ, Frédéric (1995), L'architecture métallique au XX siècle. Architecture et «savoir- faire», Paris, Belin.

SILVA, Geraldo Gomes da (1988), Arquitectura do ferro no Brasil, São Paulo, Livraria Nobel.

SOBRINO, Julian (1996), Arquitectura industrial en España, 1830-1990, Madrid, Ed. Cátedra. 